\title{
CAPITALISMO GLOBAL Y CAMBIO EDUCATIVO. LOS FUNDAMENTOS ESTRUCTURALES E IDEOLÓGICOS DE LA POLÍTICA EDUCATIVA NEOLIBERAL
}

\author{
Guillermo Miranda Camacho*
}

La reconfiguración de la hegemonía social y política del capital que se consolidó con la alianza de la Nueva Derecha (neoliberales y neoconservadores) fue una reacción a la crisis de acumulación de capital que tuvo lugar a principios de la década de 1970. Los objetivos estratégicos de este bloque hegemónico fueron básicamente la instauración del capitalismo giobalizado y el establecimiento de una hegemonía política y cultural de corte neoliberal. En este ensayo realizamos una aproximación hermenéutica, para mostrar que la irrupción del discurso educativo y la política educativa neoliberal, son elementos axiales del programa político y económico que la Nueva Derecha impulsó para enfrentar a los siguientes cambios estructurales: la crisis de acumulación del capitalismo regulado que se inicia en 1973; las crisis de legitimación y racionalidad del Estado del bienestar; el desmantelamiento del pacto keynesiano y del acuerdo socialdemócrata en educación de posguerra; la reestructuración económica frente a la crisis de acumulación; los imperativos de configuración, implantación y legitimación de la nueva estructura social de acumulación del capitalismo global; y la consolidación de la cultura hegemónica del neoliberalismo.
The reconfiguration of the social and political hegemony of the capital consolidated with the union of the New Right (neoliberals and neoconservatives) was a reaction against the crisis of capital accumulation that took place during the early 1970's. The strategic objectives of this hegemonic block were basically the re-establishment of globalized capitalism and the establishment of a neoliberal political and cultural hegemony. This essay provides an hermeneutic approach to show that the irruption of educational discourse and the neoliberal education policy are essential elements of the political and economical program promoted by the New Right as a way to face the following structural changes: the regulated crisis of capitalist accumulation that began in 1973; the crisis of legitimation and rationality of the State of contentment; the dismantling of the Keynesian pact and the sociodemocrat agreement in postwar education; the economical restructuring opposite to the accumulation crisis; the imperatives of configuration, introduction and legitimation of the new social structure of global capitalist accumulation and the consolidation of neoliberalism's hegemonic culture.

* Guillermo Miranda Camacho, Sociólogo, graduado en la Universidad Nacional (UNA), Costa Rica. Doctor en Ciencias de la Educación, Universidad de Málaga, España. Ha realizado investigaciones en el campo de la sociología de las políticas educativas, tanto en Costa Rica como en España. Actualmente es profesor de la División de Educación Rural del Centro de Investigación y Docencia en Educación-CIDE- de la UNA. 


\section{Del capitalismo regulado al capitalismo global: la configuración de una nueva estructura social de acumulación}

La tesis de fondo de este ensayo parte del reconocimiento del papel central que ocupan los procesos de acumulación de capital en la comprensión de los cambios en la estructura y dinámica de las sociedades capitalistas. Esta visión hermenéutica se sitúa en aquellas tradiciones del pensamiento social y económico que reconocen que el conjunto de transformaciones estructurales en todas las esferas de la sociedad global del capitalismo deviene en una característica inmanente al proceso de acumulación y reproducción del capital, que tiene como eje central el proceso de valorización, y en el ciclo económico su expresión histórica más significativa.

La dinámica de la acumulación de capital depende de muchas variables las cuales confluyen en distintas proporciones en la formación de su resultante monetaria y de lo que, en efecto, se constituye en su relación clave: la tasa de beneficio obtenida. La reinversión de una parte de los beneficios, de un ciclo productivo a otro, es lo que hace posible la reproducción de manera ampliada de las condiciones de producción, con lo cual el modo de producción capitalista y su estructura social permanece. Las premisas básicas en que se funfamenta este proceso son las siguientes: a) El sistema capitalista se reproduce ampliándose; b) la reinversión de una parte del beneficio es una condición de la economía capitalista; y c) la cantidad de esta inversión está determinada directamente por la tasa de beneficio media de los otros capitalistas que se relacionan a través del mercado. Moral y Raymond (1986) observan que el proceso de acumulación ampliada del capital, y por ende, la reproducción capitalista requiere como condición de posibilidad una transformación tendencial del sistema capitalista de carácter progresivo, irreversible y crecientemente complejo. En consecuencia, la acumulación ampliada requiere de una mayor inversión en cada ciclo y de una expansión del mercado en el cual vender el incremento de la producción.

La creciente complejidad que caracteriza el proceso de acumulación de capital, por la preeminencia de la economía de mercado, produce la creciente necesidad de aumentar la inversión y expansión del mercado. Esta expansión implica una modificación estructural de las relaciones sociales y, en consecuencia, de sustitución de las reglas anteriores que deben ser sustituidas por otras para asegurar la dinámica de la mercantilización, en virtud de la aparición de nuevos productos mercantiles, que se deben convertir en necesidades para el consumo masivo y que lógicamente deben ser comprados por los consumidores. En consecuencia, la dinámica de la acumulación ampliada presupone, como 
condición de posibilidad, de un entorno social e institucional que la facilite: una estructura social de acumulación ${ }^{1}$.

Según Riutort (2001: 18) la estructura social de acumulación se define como "un conjunto de articulado de hábitos, costumbres, convenciones, administraciones, contratos, derechos de propiedad, legislaciones, etc., que, para cada sociedad y época histórica, facilitan y estimulan el mantenimiento de una tasa de beneficio suficiente, por tanto, la inversión del capital". El papel de la estructura social de acumulación es central en el proceso de desarrollo del capitalismo, por tanto, su análisis deviene en indispensable para comprender las especificidades de sus grandes movimientos estructurales y las coyunturas históricas que surgen de estos. Entre sus más significativas características destacan las siguientes: a) pasa por una fase de consolidación y otra de decadencia; b) coinciden con las ondas largas de expansión y crisis del capitalismo; c) facilita la obtención de altas tasas de beneficios; d) cuando se considera que ofrece dudosas expectativas los capitalistas tienden a retraer la inversión y la economía entra en una fase de crecimiento lento que puede acabar en crisis; e) poseen características particulares que las diferencian de las otras, en virtud de las especificidades históricas de cada periodo; f) después de un periodo de consolidación y de haber coadyuvado en el proceso expansivo, se convierten en obstáculos que desaceleran el proceso, en razón de que sus particularidades no se corresponden con las nuevas exigencias del proceso de acumulación ampliada de capital. Cuando esto último sobreviene, se inicia en la estructura social de acumulación un proceso de contradicciones sociales, de conflictos, de procesos de cambio institucionales, nuevas formas de producción, experiencias innovadoras, etc., que confluyen según sus resultados económicos y los límites de la reconfiguración de la hegemonía social.

\section{La crisis de acumulación del capitalismo regulado}

En la formación social capitalista el proceso de acumulación impone, en efecto, nuevas exigencias de cambio estructural, que responden a la lógica de ese proceso, para facilitar y garantizar la acumulación ampliada de capital correspondiente a cada ciclo económico. La lógica de la acumulación de capital pone de manifiesto que el capitalismo se amplía en cada ciclo productivo y se modifica

1 Las principales articulaciones o ejes de relaciones sociales que destaca son: 1) las relaciones de los capitalistas entre sí; 2) las relaciones de los capitalistas y los trabajadores; 3) las relaciones de los trabajadores entre sí; 4) las relaciones del Estado y la economía; 5) las relaciones de los centros de localización preferente de la acumulación y las periferias y semiperiferias y 6) la relación del proceso de producción capitalista con el medio natural y humano (Riutort, 2001: 18). 
...el cambio de orientación de la política educativa, como una dimensión particular del conjunto de redefiniciones que la Nueva

Derecha promueve desde el Estado para asegurar y llevar adelante su programa hegemónico neoliberal. Entre cuyos aspectos centrales destacan las condiciones de reproducción de una estructura social y de un sistema institucional que contribuya a asegurar las exigencias reproductivas del capital, en el contexto de la crisis de acumulación del capitalismo regulado. En esta tesitura, el cambio educativo en las últimas décadas ha establecimiento de un consenso ideológico y político en la sociedad civil alrededor de ese programa político y al proceso de reestructuración de capital para posibilitar el proceso de acumulación de un capitalismo global. propendido básicamente al

internamente en la sucesión histórica de cada ciclo ${ }^{2}$. Por lo tanto, el desarrollo del capitalismo no es lineal sino que está sujeto a oscilaciones de naturaleza y duración diferentes. La tasa de beneficio del capital no cae linealmente, su caída se realiza describiendo movimientos de amplia duración en largos periodos de ascenso y de descenso. Estas oscilaciones del capital son las que Mandel (1986) denominó ondas largas de la economia capitalista que tienen una duración aproximada de cincuenta años, tanto en su fase de ascenso o prosperidad como en la de descenso o depresión. Las oscilaciones a largo plazo de la tasa de beneficio han determinado las fluctuaciones de las ondas largas del desarrollo del capitalismo.

La génesis del capitalismo comprende cuatro ondas largas, con sus fases de auge y depresión (Mandel, 1986). Las dos primeras corresponden a la Revolución Industrial: La primera, asociada a la tecnología de la manufactura, tuvo su fase de ascenso de 1793 a 1825 , y su fase de depresión se extendió hasta 1847. En la segunda, su fase de auge se extiende de mediados del siglo XIX hasta 1873, su fase de descenso concluyó en 1983; en este periodo se generalizó la utilización de la máquina de vapor. En el curso de la tercera onda, tuvo lugar la segunda fase de la Revolución Industrial, en la cual el capitalismo

2 Riutort (2001:17) destaca dos causas inmanentes de esta dinámica: $1^{\circ}$ La dinámica de la competencia entre los capitalistas induce a los competidores a establecer modificaciones en el proceso productivo con el propósito de obtener una mayor productividad (mayor cantidad de productos por hora de trabajo). Resultado de esta competencia los productores capitalistas que logran productos a menor costo, los venden más baratos, con lo que logran vender mayor cantidad y por tanto obtienen mayor beneficio con lo cual aumentan la escala de producción. Aquellos que no logran este resultado con el tiempo son desplazados por aquellos. $2^{\circ} \mathrm{La}$ introducción de innovaciones técnicas y organizativas (aumento de la composición técnica del capital) racionalizan la inversión con el ahorro de fuerza de trabajo, produciendo que al menos se iguale la productividad, o en el mejor de los casos aumente. Esta estrategia coloca a los capitalistas en una franca situación de ventaja frente a los trabajadores, al adquirir una mayor capacidad de negociación, en razón de que éstos últimos ven debilitadas sus capacidades de resistencia y de lucha social. Con lo cual se reduce el valor de la fuerza de trabajo y, en consecuencia, aumenta la tasa de beneficios del capital. 
experimentó grandes convulsiones, su fase ascendente culmina en 1914 (inicio de la Primera Guerra Mundial), y su fase descendente se extiende desde la crisis económica, que se inicia en 1929, hasta el comienzo de la Segunda Guerra Mundial. La cuarta, inicia su fase de prosperidad a partir de la conclusión de la Segunda Guerra Mundial (corresponde al periodo de la acomodación keynesiana y la Revolución Tecnológica); su fase de depresión arranca en 1973 con la crisis económica que se extiende hasta 1993. Esta última es la que nos interesa destacar para situar nuestro análisis. Nos centraremos en el periodo de prosperidad de posguerra (el largo boom), destacando dos procesos sociohistóricos:

En primer lugar, la fase de prosperidad de la posguerra es el momento en el cual se escenifica la redefinición del papel del Estado y, por ende, su reestructuración hacia un modelo intervencionista y asistencialista. Es, asimismo, un periodo en el cual el capitalismo se organiza sobre la base de un amplio consenso social respecto del crecimiento de la producción y la redistribución entre las diversas clases y grupos sociales. Fue la época del compromiso del Welfare State en el que se efectuó el desarrollo extensivo del sistema escolar de 1946 a 1973 y en el que prevaleció la lógica cuantitativa tanto en el ámbito del alumnado como de las inversiones, y en el que la simetría y complementación entre las tendencias igualitarias y el sometimiento del aparato escolar al sistema productivo marcaban la pauta (Laval, 2004). En el curso de esta fase expansiva del modelo de acumulación de capitalismo regulado, la intervención estatal anticíclica apoyadas en las políticas keynesianas, aseguraba una demanda capaz de captar los aumentos sostenidos de productividad, en los periodos recesivos del ciclo económico. El decrecimiento de la productividad -como lo explica Riutort (2001)produjo la demanda de consumo, poniendo de manifiesto el límite de esos sistemas de producción ante la descualificación del trabajo, la introducción de nuevas tecnologías, el incremento de los costes de control, las demandas sindicales por aumentos de salario, el desfase de los modelos organizacionales de producción, etc.

En esta fase, el Estado asume un papel regulador de las condiciones a partir de las cuales se lleva adelante el pacto keynesiano y el modelo de crecimiento económico: surge en el mundo capitalista el Estado del bienestar. En este pasaje Claus Offe (1990: 135) pone de relieve el significado histórico social de su irrupción en las sociedades capitalistas avanzadas:

El Estado del bienestar ha servido como principal fórmula pacificadora de las democracias capitalistas avanzadas para el periodo subsiguiente a la Segunda Guerra Mundial. Esta fórmula de paz consiste básicamente, en primer lugar, en la obligación explícita que asume el aparato estatal de suministrar asistencia y apoyo (en dinero o en especie) a los ciudadanos que sufren necesidades y riesgos específicos característicos de la sociedad mercantil; dicha asistencia se suminis- 
tra en virtud de pretensiones legales otorgadas a los ciudadanos. En segundo lugar, el Estado del bienestar se basa sobre el reconocimiento del papel formal de los sindicatos tanto en la negociación colectiva como en la formación de los planes públicos. Se considera que ambos componentes estructurales del Estado del bienestar limitan y mitigan el conflicto de clases, equilibran la asimétrica relación de poder entre trabajo y capital, y de ese modo ayudan a superar la situación de luchas paralizantes y contradicciones que constituía el rasgo más ostensible del capitalismo liberal, previo a este tipo de Estado. En suma, el Estado del bienestar ha sido celebrado a lo largo del periodo de posguerra como solución política a contradicciones sociales.

En segundo lugar, la fase de reestructuración del capital, con la consecuente reconfiguración de las fuerzas sociales y de su complejo entramado de relaciones sociales, dará lugar a la estructura social de acumulación del capitalismo regulado, como resultado del proceso de acomodación keynesiana. En esta fase el desarrollo del capitalismo se caracterizará por el crecimiento de los derechos de propiedad y los crecimientos de los derechos políticos y sociales, que produjo una tendencia a la integración de los agentes y movimientos sociales, y de los principales subsistemas institucionales. El rasgo más importante de esta estructura social de acumulación ha sido la regulación de algunos ámbitos de las relaciones sociales que se establecen entre ellos. Es por esta razón que al proceso de acumulación que se inicia desde 1945, y a la estructura social que emerge como parte de ese proceso, se les ha denominado con la categoría de capitalismo regulado; cuya fase de expansión se extiende hasta 1973, en que tiene lugar el inicio de la crisis de acumulación (Riutort, 2001).

La crisis de la racionalidad reguladora del Estado del bienestar trajo aparejada la crisis del modelo de gestión keynesiana, y, en paralelo, puso de manifiesto la obsolescencia del sistema de producción taylorista-fordista de las grandes industrias que había constituido la base de la producción económica para el consumo masivo. Entre las manifestaciones más ostensibles que caracterizaron la crisis de acumulación de capital, Sharp (1988: 159) identifica: a) la expansión de la deuda pública y de la privada que ha impedido que muchos de los países del Tercer Mundo puedan acceder a préstamos en los organismos del sistema financiero internacional, provocada por el exceso de confianza en el sistema fordista de producción y las políticas económicas keynesianas impulsadas a partir de la Segunda Guerra Mundial; b) La Tercera Revolución Tecnológica que modificó sustancialmente las aplicaciones tecnológicas del modo de producción del capitalismo tardío y que ha venido provocando un aumento de la composición orgánica del capital, con la consecuente ola de expulsión de grandes contingentes de trabajadores del sistema productivo, las 
presiones en la tasa de beneficio, la masiva sobreproducción de valores de cambio (esto se evidencia en las industrias de acero, petroquímicas, de automóviles, eléctricas y de astilleros) acompañada con una pérdida del poder adquisitivo monetario; c) la redistribución de la plusvalía a las clases propietarias de la OPEP y las clases capitalistas del Tercer Mundo como resultado de los cambios económicos y políticos de posguerra; y d) la coyuntura histórica mundial caracterizada por las crisis sociales y políticas del capitalismo que han amenazado las alianzas entre las fracciones de clase burguesas en ese periodo, la guerra fría, la pérdida de la hegemonía norteamericana sobre el sistema capitalista, la intensificación de la carrera armamentista, los conflictos y movimientos sociales de las décadas de 1960 y 1970 contra el control de la producción, los salarios, el medio ambiente, etc., que han ejercido presión sobre la tasa de beneficios y que se han tornado en obstáculos en la reestructuración del capital.

\section{La estructura social de acumulación del capitalismo global}

El cambio de una estructura social de acumulación por otra implica (en su primera fase) la contradicción estructural de la coexistencia de la estructura social de acumulación nueva y la que tiende a desaparecer (Riutort, 2001: 18-20). Este proceso de cambios estructurales correspondientes a las fases de ascenso y descenso de la crisis de acumulación de capital, caracterizado por continuidades y discontinuidades, se manifiestan en las distintas esferas de la sociedad civil en su conjunto, es de una extrema complejidad y está profundamente determinado por debates ideológicos políticos, económicos, culturales, educativos, etc., que hacen emerger -como lo analizaremos más adelante- ciertos modelos de discurso ideológico que ponen en paralelo de las fases de ascenso y descenso del proceso de acumulación.

La tendencia expansiva del Estado del bienestar se invirtió en el decenio de 1970, produciendo una contradicción entre el crecimiento del capital y los sectores no mercantilizados que se manifestó como crisis de acumulación y del Estado del bienestar. En esta coyuntura histórica las clases capitalistas se enfrentan al desafío de iniciar la reestructuración del capital y una recomposición de las fuerzas sociales y políticas, una realineación de los modelos de clases tradicionales y la búsqueda de otras alianzas. Este proceso complejo se manifiesta, según Offe, en su doble condición de ser una crisis de racionalidad de los fundamentos que lo erigieron y, al mismo tiempo, una crisis de legitimación. Sobre este aspecto señala:

La aguda recesión económica de mediados de los años setenta ha producido un renacimiento intelectual y políticamente poderoso de neo-laissez faire y doctrinas económicas monetaristas. Esas doctrinas 
equivalen a una crítica fundamental del Estado del bienestar, que se considera la enfermedad de aquello que pretende curar; en vez de armonizar los conflictos de una sociedad mercantil, los exacerba e impide que las fuerzas sociales de paz y progreso (a saber: las fuerzas del mercado) funcionen de modo apropiado y benéfico (Offe, 1990: 137).

La nueva globalización, como forma de expansión de capital ha producido una pérdida en la eficiencia de la gestión económica de los Estados nacionales, sin que esto signifique poner en peligro su existencia. A este respecto hay que destacar que la acción reguladora del Estado se desbordó al dejar fuera de su alcance las relaciones básicas del sistema económico. La contradicción insuperable para el capitalismo, según Amín (1999), radica en que el capitalismo no solo es un sistema económico: su economía requiere de una dimensión social y política, lo que implica un Estado. Históricamente el capitalismo monopolista requirió para la acumulación de capital del Estado-nación que conformaba la base de la estructura económica mundial y representaba el espacio en que convergían la reproducción de la acumulación y el espacio de su gestión social y política. En la actualidad, el capitalismo global requiere para su expansión de un espacio mundializado de gestión económica del capitalismo y los espacios nacionales de su gestión social y política.

Ello explica el resurgimiento del "mito secular del nacionalismo" y del discurso nacionalista sustentado racionalmente en supuestas amenazas endógenas o exógenas de las naciones, y por el cual se justifica todo tipo de acción encaminada a proteger o defender los intereses nacionales. Con el reaganismo, thatcherismo y el kholismo este proceso se puso claramente de manifiesto. Las acciones contra los sindicatos que con las huelgas socavan el "interés nacional", la amenaza de naciones hostiles que legitima el rearme, una mayor consolidación de poder entre los países del Tercer Mundo y la racionalización política de un Estado fuerte para “detener la decadencia histórica de 'nuestra' nación frente a las demás” (Sharp, 1988: 163), son algunos de los fundamentos ideológicos del corpus ideológico neoliberal y neoconservador promovido por la Nueva Derecha. Es en este contexto del impulso al establecimiento del capitalismo global que emerge el programa político neoliberal, del cual la reorientación de las funciones económicas, políticas, sociales y culturales de la educación son partes integrantes fundamentales. Esto se pone en evidencia tanto en la formulación discursiva de las políticas educativas como de sus acciones prácticas que se impulsan en el conjunto del sistema educativo. 
Según el diagnóstico en que se basa el programa político de la Nueva Derecha, la educación ha sido uno de los principales factores que han contribuido en el establecimiento de este nuevo statu quo en la sociedad contemporánea; por lo cual se propone un cambio educativo orientado a recuperar, desde una "racionalización moralista" conservadora, la legitimación de su programa político neoliberal. Nos detendremos a analizar dos dimensiones que en nuestra opinión son fundamentales para la comprensión de la política educativa en las sociedades de capitalismo avanzado. La primera de naturaleza estructural, que comprende la articulación entre la crisis de acumulación del capitalismo regulado que se inicia a partir de la década de 1970, la irrupción de las nuevas fuerzas sociales, la reestructuración del capital que han impulsado ante esa crisis, y la reestructuración del papel de la educación y del sistema educativo en el marco de esos procesos. La segunda, de naturaleza superestructural que incluye los fundamentos ideológicos y programáticos en que se sustenta la reconfiguración del nuevo proceso hegemónico educativo, como una expresión particular de la legitimación del programa político neoliberal.

\section{La Nueva Derecha: una alianza estratégica de clases entre neoliberales y neoconservadores}

Respecto de la irrupción de la Nueva Derecha, Offe (1990: 137) argumenta que la recesión económica de mediados de los setentas produjo el renacimiento intelectual y políticamente poderoso del nuevo neo-laissez faire y doctrinas económicas monetaristas. Doctrinas a partir de las cuales se realiza una crítica que tiene como blanco el Estado del bienestar, que "se considera la enfermedad de aquello que pretende curar; en vez de armonizar los conflictos de una sociedad mercantil, los exacerba e impide que las fuerzas sociales de paz y progreso (a saber las fuerzas del mercado) funcionen de modo apropiado y benéfico". Siendo el Estado del bienestar la expresión paradigmática de la armonización de intereses económicos, sociales y políticos es lógico que la Nueva Derecha haya diseñado una estrategia de ruptura de la acomodación keynesiana entre los derechos de propiedad y los derechos sociales y políticos, proponiendo un ajuste a las nuevas condiciones estructurales de la crisis de acumulación del capitalismo regulado. Así pues, la Nueva Derecha ha retomado el modelo económico liberal de hace siglo y medio con una renovada racionalidad económica y política que se manifiesta en dos grandes ámbitos: el capitalismo globalizado y la hegemonía política y cultural del neoliberalismo. El interés común de los neoliberales y 
los neoconservadores consiste básicamente en la instauración plena de una economía capitalista de mercado globalizada y el resurgimiento, con una "actualizada" racionalización ideológica, de antiguas tesis ideológicas conservadoras, ante el temor a los riesgos y amenazas que presenta la "degradación" de las actuales sociedades.

El programa político resultante de esta armonización de intereses se articula en torno a dos ejes ideológicos básicos: por un lado, la defensa e instauración total del capitalismo de mercado, en aras de la consecuente expansión y permanencia a escala mundial de la acumulación de capital, como respuesta a la crisis capitalista y la crisis de legitimación y racionalidad del Estado del bienestar; y por el otro, en el establecimiento de una hegemonía política y cultural neoconservadora que restablezca el antiguo orden, ante la crisis de legitimación y las amenazas de cambios sociales y culturales que, según la visión del neoconservadurismo, han trastocado los fundamentos morales en que se erige la sociedad capitalista. Acerca del surgimiento del neoconservadurismo, Goodwin explica que:

(...) en los últimos diez años aproximadamente, se ha visto resurgir en Occidente una nueva variante ideológica del conservadurismo, la 'derecha revolucionaria'. El libertarianismo de derechas y las teorías neoconservadoras se han desarrollado como reacción contra la socialdemocracia y el liberalismo del bienestar ${ }^{3}$. En la economía, los nuevos conservadores adoptan la concepción del laissez-faire de Hayek. Favorecen la privatización de las empresas nacionales y estatales y la desaparición de las reglas que regulan el comportamiento de los mercados (por ejemplo, la reducción de las leyes que protegen el empleo, los reglamentos sobre seguridad en la construcción, etc.), para fomentar la actividad económica y los negocios. Los servicios sociales deben ser recortados o abolidos: las personas deben ser obligadas a depender de sí mismas (1998: 203).

Según Apple (1996: 30), la alianza de la Nueva Derecha combina una amplia cobertura con cuatro grupos principales que mencionamos a modo de ejemplo: a) las élites económicas y políticas dominantes que promueven una modernización de la economía; b) un sector de la clase trabajadora, "de raza blanca y de clase media" que desconfían del Estado y cuya preocupación fundamental es la seguridad, la familia, el saber y los valores tradicionales (denominados "populistas autoritarios"); c) los conservadores económicos y culturales, que preconizan por vuelta a la disciplina y la competencia del darwinismo social; y d) un

3 Una conspicua expresión en Costa Rica es el Movimiento Libertario, con una presencia muy activa en la escena política y como partido minoritario en la Asamblea Legislativa. 
sector de la nueva clase media, que aunque no concuerde con esos otros grupos, pero que tiene intereses profesionales de progreso y dependen del empleo generalizado de la rendición de cuentas, la eficiencia y los procedimientos de gestión. Aunque esto está referido a los Estados Unidos es un claro ejemplo de las tendencias generales de recomposición social de las clases, sectores y grupos sociales que aglutina esta alianza de clases alrededor de intereses comunes.

La orientación económica esencial del programa neoliberal de la Nueva Derecha tiene como centro gravitatorio la globalización de la economía mundial que surge con las inherentes contradicciones propias del sistema capitalista, cuya condición sine qua non es la configuración de una estructura social de acumulación que posibiliten el proceso de acumulación ampliado de capital. Acerca del modelo neoliberal Navarro (2000: 89) expresa:

El triunfo del neoliberalismo, con el presidente Reagan en EE. UU. y la señora Thatcher en Gran Bretaña, así como el colapso de la Unión Soviética, significa la expansión y dominio internacional del modelo neoliberal, detrás del cual están los intereses de clase que representa (...). Los países neoliberales son aquellos que presentan un mayor dominio y mayor influencia del mundo empresarial y menor poder del mundo laboral. Representa el polo opuesto a la socialdemocracia, a la que intenta presentar por parte de las fuerzas liberales como un proyecto irrelevante e ineficaz, y ello a pesar de la evidencia mostrada en este capítulo de que los países socialdemócratas han sido más eficientes y exitosos en sus políticas económicas y sociales que los países liberales. A pesar de esta evidencia, el modelo liberal se ha globalizado (es decir, internacionalizado) a través de su gran influencia en las agencias y en los medios internacionales (tanto financieros como económicos, culturales y políticos) en respuesta a los intereses de clase que representa. En este discurso y práctica, los intereses de la clase dominante se presentan como los intereses universales.

\section{Las crisis de legitimación del Estado del bienestar y el cambio educativo neoliberal}

En el conjunto del programa político neoliberal de la Nueva Derecha el papel de la educación ha asumido, como estrategia hegemónica fundamental, la consolidación de una unidad social y cultural a través del consenso alrededor de los derechos de propiedad y los valores del individualismo posesivo y del neocorporativismo. En esto radica la dirección ideológica que las clases dirigentes 
de esta alianza ha venido promoviendo, en la búsqueda de un total desplazamiento de los valores solidarios implantados por las políticas de corte socialdemócrata. Desde el punto de vista de las políticas educativas Apple (1996: 29) indica que: "Muchas políticas de derechas que ocupan en la actualidad el centro del escenario de la educación y de casi todo lo demás suponen una tensión entre el énfasis neoliberal en los 'valores del mercado', por una parte, y el apego neoconservador a los 'valores tradicionales', por otra”. Se trata ciertamente de imponer un cambio cultural que persigue la entronización de los llamados valores posmateriales.

En épocas de grandes transformaciones -afirma Apple (2000: 8283), estos conflictos se vuelven incluso más intensos y, dado el actual equilibrio de poder en la sociedad, los defensores de los derechos de propiedad han podido, una vez, promover sus reivindicaciones por la restauración y expansión de sus prerrogativas no sólo en educación, sino en todas nuestras instituciones sociales.

En el fondo del cambio cultural que impulsa la alianza de la Nueva Derecha subyace la intencionalidad de "modelar" un nuevo tipo de ciudadanía, que conviva, participe, enriquezca, pero por sobre todo legitime y asegure la permanencia de la cultura hegemónica neoliberal y neoconservadora en la sociedad civil. Desde esta óptica, es posible identificar dos factores sociohistóricos estrechamente vinculados que han estado a la base del origen del proceso reciente del cambio educativo neoliberal:

En primer lugar, considerando que el capital requiere encontrar una reestructuración para poder conservar el control e iniciar una nueva fase de reproducción ampliada, los imperativos cambios estructurales derivados de la crisis de acumulación a la que se enfrentaron los países de capitalismo avanzado han puesto de relieve la urgente necesidad de reestructuración de sus capitales (Sharp, 1988). Esta reestructuración del capital acontece en un momento histórico del desarrollo del capitalismo en el que el Estado no es capaz de tener un control total del proceso anárquico de producción mercantil, si bien, como lo señala Habermas (1999: 96), "pone ciertos límites a la producción capitalista, pero no la domina como una instancia de planificación del capitalismo en su conjunto”. Según el planteamiento de Habermas (1999) el Estado intervencionista a diferencia del Estado liberal, se incorpora en el proceso de la reproducción, esto es, no solo se limita a asegurar las condiciones generales de la producción, sino que se convierte en un ejecutor de la ley del valor; en cierto sentido se somete a ella, y porello la acción administrativa en el largo plazo más bien tiende a agravar la crisis económica. 
Este proceso, como se verá, provoca la crisis de racionalidad y de legitimidad que acompañó la crisis de acumulación del capitalismo regulado.

Respecto de las causas que provocaron la crisis del modelo de acumulación de posguerra de la década de 1970, Claus Offe (1990) sostiene la tesis de que el Estado del bienestar que logró gestionar la crisis en el curso de la fase de expansión capitalista, desde 1946 hasta inicio de la década de 1970, llegó al límite de capacidad para atender la gestión de los problemas derivados de la valorización del capital. Con el excesivo crecimiento de su aparato -una suerte de hipertrofia- el Estado comprometió su capacidad reguladora y perdió su capacidad de incidir en el proceso de valorización del capital ${ }^{4}$. El modelo de acumulación del capitalismo regulado entra en crisis cuando el Estado que había creado un enorme aparato y paquetes de normas reguladoras del periodo de posguerra hasta los setentas no pudo gestionar las tendencias de esa crisis. En consecuencia, las causas no obedecieron a una exclusiva incapacidad técnica estatal, sino a un problema estructural del modelo que se manifestó en el largo plazo: la regulación estatal keynesiana y las políticas sociales del bienestar provocaron la crisis de racionalidad del Estado del bienestar. Para Offe la crisis de los setentas es una crisis de la conducción de la crisis.

En segundo lugar, la ruptura del acuerdo socialdemócrata en educación ocurrido en la década de 1960 y parte de la de 1970, ha sido uno de los factores causantes de la aparición del viraje ideológico que ha experimentado la educación desde inicios de los ochentas. Acerca de este proceso Apple (2000: 153) comenta que se ha producido una fractura en el acuerdo que orientó la política educativa desde la Segunda Guerra Mundial promovida por "los grupos más poderosos dentro del gobierno y la economía y dentro de los movimientos sociales del "populismo autoritario"', quienes han cambiado los términos del debate relativos a la educación, el bienestar social y otras áreas del bien común. Esta transformación de los fines de la escuela abandona el programa socialdemócrata que concebía la educación como parte de una alianza social, que definía como centro gravitacional de la acción estatal la formulación y puesta en práctica de políticas sociales, orientadas a favorecer a las clases subalternas y los grupos sociales minoritarios o marginales. En el campo social la lucha por la desigualdad social y los excesos del mercado se compensaba con políticas asistencialistas del Estado del bienestar, entre las cuales la ampliación de las oportunidades de educación ocupaba un lugar central y se complementaba con acciones compensatorias, para que la

4 “El Estado es -como lo expresa Fernández Durán (2001: 126)- una poderosa, costosa, compleja, burocrátic jerarquizada y antidemocrática esiructura que necesita también del crecimiento económico continuo para mantenerse. $Y$, por consiguiente, la inviabiliảad del crecimiento económico continuo en el futuro, socava también su propia capacidad de mantenimiento en el porvenir". 
niñez y la juventud de los sectores sociales empobrecidos pudiesen tener las condiciones mínimas para hacer realidad su derecho a la educación.

Esa ruptura se profundizó en la década de los ochentas -como lo pone de relieve Fernández Enguita (1990: 24)- por una dinámica muy distinta a las de las dos décadas anteriores, principalmente un contexto de crisis económica mundial en el cual "la atomística dinámica del descontento individual ha hecho sombra a la dinámica colectiva", y en el que "los gobiemos socialdemócratas han sido barridos por opciones conservadoras radicalizadas o se han adaptado por símismos a la tónica marcada por la 'Nueva Derecha' y el neoliberalismo económico".

Para profundizar más en la lógica de la visión que hemos venido desarrollando cabe preguntarse a estas alturas de nuestra exposición: ¿En qué consisten los problemas estructurales del modelo de acumulación del capitalismo regulado? ¿Cuáles son las principales dimensiones de la crisis de legitimación y de racionalidad del Estado del bienestar? ¿Cuál es la vinculación entre esas crisis y el cambio educativo? Para contestar estas preguntas recurriremos a los aportes teórico-metodológicos de Habermas (1999) relativos a la teoría de la crisis de legitimación y la teoría de las crisis sistémicas desplazadas.

Al referirse a las tendencias de la crisis económica, Habermas (1999: 8890) aclara que si en el capitalismo tardío persisten las crisis económicas, la intervención estatal en el proceso de valorización obedece a los problemas estructurales que se derivan del funcionamiento de las leyes económicas, y a la lógica de la crisis económica que se manifiesta básicamente en la tendencia decreciente de la cuota de ganancia. Esto implica que el Estado continúa la política del capital con otros medios, recurriendo a mecanismos de autorregulación del proceso de valorización del capital a través del poder legítimo. Ante el hecho de que la crisis está determinada por la ley del valor, haciendo prevalecer "la asimetría de raíz estructural prevaleciente en el intercambio de trabajo asalariado por capital", el Estado no puede en definitiva contrarrestar la tendencia al descenso de la cuota de ganancia. Lo máximo que puede hacer es introducir mediaciones políticas (con instrumentos y medios de política económica) para influir en su resultado final. De ahí se sigue, que la tendencia de la crisis económica se impondrá a través de la crisis social y, por consiguiente, llevará a luchas políticas entre los propietarios del capital y la masa asalariada. En la coyuntura de la ruptura del pacto socialdemócrata en educación tuvo lugar, asimismo, la pérdida de peso social de las organizaciones sindicales, el pleno empleo pasó a ser desempleo masivo, y la preocupación mayor fue la de conservar los puestos en vez de transformarlos. Complementariamente, hay que destacar que la Nueva Derecha logró apartar sectores importantes de la clase obrera y de la nueva pequeña burguesía de su identificación con el reformismo socialdemócrata. 
Según la tesis del capitalismo monopolista de Estado la valorización del capital ya no regula el proceso capitalista. El Estado interviene, regulando los intereses de las grandes corporaciones y del proceso general de valorización. Por tal razón, la crisis económica adquiere formas políticas. Este planteamiento se aparta de la tesis del marxismo ortodoxo que formula que el Estado adquiere el papel de "capitalista genérico" que interviene en la revalorización del capital y en las consecuencias que se derivan de ese proceso. Desde la perspectiva de Habermas (1999), el Estado establece mecanismos de intervención enmarcados en una estrategia de economía de planificación central, por la cual modifica los principios de regulación tendente a asegurar y complementar los mecanismos del mercado. De esta manera, la regulación incide en la plusvalía, la estructura política de los salarios y las necesidades de legitimación del sistema político. Los valores de uso son asumidos por el Estado del bienestar con presupuestos de origen público, cuando el Estado pierde la capacidad de atenuar la contradicción latente aparece la crisis de legitimación.

Resulta claro de lo anterior, que las crisis económicas son gestionadas por el Estado. Desde esta óptica, es empíricamente plausible determinar el inicio de la crisis económica y la capacidad estatal de afrontarla (Riutort, 2001: 224-225). Como lo indica Habermas:

Déficit de racionalidad de la administración pública significa que el aparato del Estado, en determinadas condiciones, no puede aportar al sistema económico suficientes rendimientos positivos de autogobierno. Déficit de legitimación significa que con medios administrativos no pueden producirse, o conservarse en la medida requerida, estructuras normativas pertinentes para la legitimación. El sistema político, en el curso del desarrollo capitalista, ha desplazado sus límites hacia el interior del sistema cultural, y no sólo del económico (1999: 90).

Una consecuencia importante a resaltar es que cuando a raíz del déficit de racionalidad administrativa falla la oferta de valores de uso, cuyo objetivo es mantener el consenso de la sociedad, se produce un déficit de legitimación. En consecuencia, la integración social se ve afectada -según Habermas (1999: 91)- al depender de los aportes del sistema sociocultural, "de las motivaciones que produce en el sistema político en forma de legitimación; e indirectamente de las motivaciones de rendimiento que produce para el sistema de formación y de profesiones".

Así pues, la crisis cultural se pone de manifiesto cuando la transformación de las estructuras normativas perturba la complementariedad entre los requerimientos del aparato de Estado y del sistema educativo, y, por tanto, las expectativas 
legítimas de los miembros de la sociedad. Al desplazarse la crisis desde el sistema económico hasta el sistema cultural, el sistema educativo -como elemento axial de integración sociocultural- requería de una profunda transformación estructural y de sus fundamentos ideológicos para superar el déficit de legitimación e imponer la legitimidad del orden neoliberal. De esta forma, las políticas educativas neoliberales se han constituido en un elemento decisivo en la estrategia de legitimación de la cultura hegemónica que ha venido instaurando la Nueva Derecha.

En el capitalismo tardio, -apunta Habermas con singular precisión-tales tendencias se perfilan tanto en el plano de la tradición cultural (sistemas morales, imágenes del mundo) como en el cambio estructural del sistema educativo (escuela, familia, medios de comunicación de masas). Así, el acervo de tradición, que en el capitalismo liberal infundió vida al Estado y al sistema de trabajo social, es agotado (despojamiento de las coberturas de la tradición); además ciertos pilares de la ideología burguesa se vuelven cuestionables (amenaza del privatismo civil y al privatismo familiar y profesional) (1999: 92; lo destacado es nuestro).

En conclusión, este conjunto de cambios estructurales pone de relieve sintéticamente los principales rasgos de la crisis de acumulación del capitalismo regulado y de legitimación del programa reformista. Asimismo, explican las razones fundamentales que condicionaron, por una parte, el surgimiento de sus discursos hegemónicos contrapuestos a los discursos populistas y socialdemócratas predominantes en las políticas estatales e internacionales, en el curso del periodo de posguerra hasta la década de los setentas y ochentas.

Desde la aproximación crítica que hemos venido desarrollando, la siguiente hipótesis de Offe representa una significativa contribución en la comprensión de las bases estructurales que explican la emergencia, formulación, puesta en práctica y legitimación de las políticas educativas neoliberales:

Nuestra hipótesis es que las tendencias y las motivaciones de la politica educativa pueden ser explicadas en buena medida como una reacción a los problemas estructurales de legitimación por parte de una sociedad que invalida y desacredita continuamente sus propias premisas igualitarias (Citado por García, 1991: 148). 


\section{El programa político de la nueva derecha y el proceso hegemónico}

educativo neoliberal

Según la construcción interpretativa que hemos venido desarrollando el proceso de acumulación de capital requiere de una estructura social de acumulación que confiera soporte y continuidad. Pero, al mismo tiempo, de un marco ideológico que, desde el punto de vista hegemónico, le confiera racionalidad y legitimidad en la sociedad civil a sendos procesos. Rachel Sharp (1988: 161) hace la singular observación de que la estructura del modo de producción capitalista genera y permite que emerjan ciertos modelos de discurso ideológico, correspondientes a las fases de ascenso y descenso de las crisis de acumulación de capital y que establecen entre sí relaciones dialécticas. Esta tesis aporta una clave fundamental para comprender, a partir de los fundamentos estructurales expuestos, el contenido y significado hegemónico del discurso del programa político de la Nueva Derecha, y, por consiguiente, del cambio del discurso ideológico de la política educativa que se realiza en el contexto de ese programa.

Para el logro de sus intereses de clase la Nueva Derecha ha articulado un discurso hegemónico, en el plano ideológico, que integra elementos de la racionalidad del liberalismo clásico, de la crítica a la racionalidad reguladora del Estado del bienestar y del reformismo socialdemócrata, y de una justificación de la vuelta conservadora a los valores tradicionales. La "lectura" analítica y crítica de los fundamentos ideológicos del programa político neoliberal, como síntesis de carácter doctrinal de ambas ideologías, debe realizarse, por consiguiente, no solamente en el ámbito exclusivo de la racionalidad de su formulación discursiva (como sistemadoctrinal), sino también debe concebirse en la lógica racional de un discurso que representa una contrapartida al modelo ideológico socialdemócrata, correspondiente al proceso de acumulación del capitalismo regulado en su fase de descenso. En el curso de la fase de prosperidad de la onda larga del capitalismo posterior a la Segunda Guerra Mundial prevaleció, por las razones que hemos venido explicando, la visión estrechamente vinculada al concepto de capital humano y al programa "desarrollista" de una relación casi simétrica entre el papel del sistema de formación y la estructuración del mercado laboral. Acerca de esta cuestión García (1991: 137) explica que:

La ideología dominante en las sociedades de capitalismo maduro ha conectado el crecimiento de la instrucción escolar de masas, por una parte, a la expansión económica, y por otra, al propósito de fomentar la igualdad de oportunidades. Mientras fue posible seguir creyendo que los incrementos de la escolaridad eran tan funcionales a la acumulación productiva como a la legitimación del orden social, esta ideología apenas conoció fisuras. Pero ya no es enteramente el caso hoy (y cada vez menos). 
Ese cambio de visión que manifiesta un creciente pesimismo de ese papel del sistema escolar ha sido ciertamente aprovechado por los promotores del orden neoliberal, quienes han propiciado un cambio en los sistemas de enseñanza de los sistemas capitalistas y del papel que ha desempeñado la ideología en el contexto de la crisis estructural. El desplazamiento ha tenido como centro gravitatorio las funciones económicas de la educación en la reproducción de la fuerza de rabajo (selección y asignación de la fuerza de trabajo activa y del ejército de reserva) y en la inculcación de una disciplina acorde con la economía de mercado.

\section{La hegemonía política y cultural del neoliberalismo}

Respecto de la restauración derechista y su lucha política por la hegemonía de la sociedad civil Apple (2000) explica que estos procesos tienen como objetivos principales la lucha en varios terrenos diferentes al mismo tiempo, no solo el económico, sino también el educativo y otras áreas; esta estrategia se basa en la comprensión de que la dominación y la reestructuración de la formación social, debe acompañarse de un "liderazgo político, moral e intelectual": "Así, como reconocen tan claramente el reaganismo y el thatcherismo, para triunfar en el Estado hay que triunfar también en la sociedad civil. Como diría el notable teórico político italiano Antonio Gramsci, lo que estamos presenciando es una guerra de posiciones" (Apple, 2000: 87). De esta manera, la hegemonía política y cultural se constituye en el centro de la estrategia neoliberal y neoconservadora, y la sociedad civil en el espacio de realización de la hegemonía del individualismo posesivo. Ya la sociedad civil no es, como lo preconizaba la socialdemocracia, el espacio donde el individuo, rige su propio destino y se realiza como persona en el marco de una ética social basada en el bien común. Ahora, con la posición del neoconservadurismo, la sociedad civil deviene en el medio para asegurar que la "brecha social" -por la que los socialdemócratas desplegaron ingentes esfuerzos de reformas sociales a través de la intervención estatal en aras de una sociedad mesoclasista- se convierta en una estructura abierta donde las desigualdades de riqueza, prestigio y poder sean el reflejo de las diferencias humanas. El "nosotros" solidario, en el marco de la búsqueda del bien comín, se transforma en el "nosotros" del egoísmo privatista, deshumanizado, de los que solo conciben la vida social como un medio de canalizar sus intereses particulares de clase económica y política dominante.

La legitimación política y social de la desigualdad social asume una doble dimensión: la de una racionalidad económica, política y cultural en que priva el interés privado; y la de un sistema ideológico que racionaliza la sociedad de los méritos personales. Al referirse al papel que le confieren a la educación la Nueva 
Derecha, Apple (1996: 33) afirma: "Tanto para los neoliberales como para los neoconservadores, la tarea educativa 'no consiste en estimular a los participantes en economía de mercado para que piensen en símismos como individuos con el fin de maximizar sus propios beneficios'. Éste es un objetivo crucial, pero va mucho más allá. Las personas necesitan también que se les estimule para aceptar que tiene todo el sentido 'que haya ganadores y perdedores en el sistema'. Un proceso de este tipo 'crea riqueza'”. Esta frase pone de relieve sintéticamente cómo la política educativa de la Nueva Derecha propende hacia una sociedad civil que sea el reflejo de una sociedad abierta, jerarquizada, y meritocrática cuya orientación política está definida por quienes han "triunfado" en la escena política por sus méritos individuales. Y, por lo tanto, tienen el mérito ganado y "legitimado socialmente" de convertirse en una "clase rectora": una minoría política que como clase dirigente tiene el poder de guiar y mediatizar la conducta de la mayoría (Eccleshall, 1993).

La contribución de la escuela en el proceso de legitimación es decisiva. Para Apple (2000: 115) las instituciones escolares constituyen efectivos agentes de legitimación de grupos sociales que al mismo tiempo "recrean", mantienen y construyen permanentemente ideologías sociales y culturales que tienden a describirse a sí mismas y a la sociedad como meritocráticas. Igualmente, indica que por pertenecer al aparato de Estado, es decir, por ser instituciones políticas, requieren permanentemente de legitimarse a sí mismas. Este proceso de legitimación requiere de la exigencia de obtener el consenso de las clases subalternas, aunque no siempre los requerimientos de la legitimación política estén en correspondencia con los requerimientos de la economía. En contextos de crisis económicas el papel legitimador de la escuela se ve reforzado, en virtud de que la crisis de acumulación conlleva necesariamente una crisis de legitimación del programa hegemónico de la clase capitalista. El quid de esta cuestión consiste en que la crisis de la racionalidad administrativa ocurre -en clave habermasiana del análisis de la crisis de la legitimación- cuando la crisis económica obliga al Estado a responder en términos contradictorios a los que no es posible ofrecer una respuesta coherente. Las acciones estatales para administrar las crisis, según el planteamiento habermasiano, se traducen en intervenciones y servicios para evitar la crisis.

No obstante, las diferencias ideológicas existentes entre el neoliberalismo y el neoconservadurismo, ambas ideologías se integran en una unidad doctrinal. El núcleo ideológico axial alrededor del cual se construye el sistema de significados y representaciones simbólicas de ese discurso legitimador está integrado básicamente por cinco ejes ideológicos: $1^{\circ}$ la supremacía de las leyes del mercado capitalista como fuente esencial de riqueza, crecimiento económico y estabilidad social y política; $2^{\circ}$ su decidida oposición al Estado del bienestar y a su 
programa de bienestar social; $3^{\circ}$ la privatización y desregulación de las esferas de áreas y servicios tradicionalmente públicos y de control estatal; $4^{\circ}$ una concepción exacerbada del individualismo (una suerte de "sobreindividualismo"): el denominado individualismo posesivo; y $5^{\circ}$ el retorno a los valores y tradiciones del pasado. Estos principios integran, desde sus particulares concepciones ideológicas el corpus doctrinal del programa político de la Nueva Derecha, del que es parte integrante su particular visión del cambio educativo. Por consiguiente, en toda la tematización que integra el programa político de la Nueva Derecha y de sus políticas educativas están presentes e integrados, de manera implícita o explícita, a estos principios que se constituyen en la base de la racionalidad, racionalización y legitimación de su fundamento discursivo.

\section{La estrategia de la Nueva Derecha frente a la crisis de legitimación: el papel del sistema educativo}

La reestructuración del capital, la recomposición social de las fuerzas sociales que la promueven, y la legitimación política e ideológica de estos procesos, definen a nuestro entender, el marco interpretativo de la función educativa y del modelo de organización del sistema escolar con el sistema productivo. Concretamente, nos referimos a la articulación orgánica entre las esferas de la base estructural y el plano superestructural, en el significado económico, sociopolítico y cultural que le confirió Gramsci (1985). Para enfrentar la crisis de acumulación de capital las clases políticas despliegan estrategias de largo alcance tendientes a articular y buscar el consenso respecto de sus intereses clasistas, en aras de la recomposición de las relaciones sociales necesarias para superar esa crisis y reimpulsar la dinámica de la acumulación ampliada. Esta contraofensiva, como hegemonía política y cultural de la alianza de la Nueva Derecha, según Riutort (2001:70) se articula en torno a dos estrategias:

$1^{\circ}$ La estrategia neoliberal que es una suerte de nueva acomodación neoliberal que concilia intereses de las burguesías nacionales y transnacionales, que se sustenta en dos razones complementarias: a) la reacción del gran capital que promueve un ataque a los derechos sociales y a los movimientos y organizaciones sociales y políticas que los han defendido; y, b)la reinstauración de la primacía de los derechos de la gran propiedad y el mercado, sobre cualquier otro tipo de demandas de derechos. Gintis, por su parte, distingue dos tipos de derechos. Por una parte, los derechos de propiedad, que le confieren a los individuos el poder de participar en las relaciones sociales a partir de su propiedad, entre los cuales menciona: los derechos económicos 
de uso irrestricto, libre contratación e intercambio voluntario, derechos políticos de participación e influencia, y los derechos culturales de acceso a los medios sociales para la transmisión del conocimiento y la reproducción y transformación de la conciencia. Y por otra, los derechos de las personas que les otorga a los individuos el mismo poder, pero a partir de su pertenencia a la colectividad social: trato igualitario a los ciudadanos, libertad de expresión y movimiento, un acceso igualitario a la participación en la toma de decisiones en las instituciones sociales y reciprocidad en las relaciones de poder y autoridad (Gintis, 1980; citado por Apple, 2000: 82 ).

$2^{\circ}$ La estrategia neoconservadora de algunos sectores del capital y la derecha que preconiza la reconducción de ámbitos privados que se habían politizado a su "estadio tradicional" tales comola autoridad de la familia patriarcal, la comunidad local y las creencias religiosas 5 . Por otra parte, Riutort (2001: 70) observa que han surgido en algunos países desde el centro, la derecha y la izquierda posiciones neocorporativistas que trataban de gobernar la transformación por medio de un consenso, minimizando el coste en derechos sociales reconocidos, eludiendo los mecanismos democráticos de representación e imponiendo mecanismos funcionales de representación de sus intereses.

El Estado del bienestar con su estrategia intervencionista que establecía regulaciones para el mantenimiento del equilibrio entre los derechos individuales y los derechos colectivos, se convierte, como lo hemos explicado, en el blanco del programa hegemónico de la Nueva Derecha. El establecimiento de un marco regulador complementado con la canalización de recursos para el sostenimiento de políticas sociales, tenía un doble propósito: por una parte, la armonización de intereses de las clases y grupos sociales; de otra, el mantenimiento de la paz social y la estabilidad política. Ambas acciones se constituían en condiciones de posibilidad para la expansión de capital y en condición básica para la acumulación. Por ello, cuando las posibilidades de expansión de capital se vieron limitadas y se inició la crisis, el objetivo principal de las clases políticas adversarias del Estado del bienestar y sus políticas reformistas fue su desmantelamiento y, por tanto, la desarticulación de la sociedad del bienestar. Esto situó en el centro de sus principales estrategias políticas la reducción del sistema de seguridad social a su mínima expresión.

Un aspecto aparentemente paradójico de la actual política conservadora -afirma Bárbara Goodwin (1998: 204)- es la disminución del papel

5 Al respecto Norbento Bobbio (1999: 114) afirma: "El alma de la derecha puede ser expresada sintéticamente con el lema: 'Nada fuera ni en contra de ia tradición, todo en y por la tradición'". 
del Estado como agení e económico y distribuidor del bienestar (a medida que van anulándose o recortándose los servicios sociales), política que se propone simultáneamente con la extensión de su papel en términos de control social y de control sobre los gobierno locales. El mantenimiento de la ley y el orden es un aspecto importante de la política del gobierno, y los poderes estatales de control han sido fortalecidos por encima de los sindicatos y de otros consejos locales 'rebeldes' que desafian la política del gobierno e intentan reafirmar su autonomía.

Esto apunta a un rasgo que a nuestro juicio es fundamental en la estrategia política de la Nueva Derecha, que es reforzar el control social recurriendo al expediente de la legalidad para imponer su programa político (incluso en las políticas educativas). Este estilo de gobierno, basado en lo que llamamos un "autoritarismo legalista", es una conspicua manifestación del neoautoritarismo que caracteriza la gestión gubernamental de la Nueva Derecha.

En materia de gastos públicos en educación las tensiones entre políticas educativas conservadoras y reformistas ya se manifestaban desde los años ochentas entre dos posiciones divergentes: una que propugna por una reducción de los gastos públicos en educación, argumentando que por medio de tal medida se le haría frente al desequilibrio entre las estructuras escolares y las laborales, con lo cual persiguen reducir la cantidad de los aspirantes a empleos cualificados; y otra, que plantea que la reducción del presupuesto educativo impide que el sistema educativo continuase siendo un instrumento fundamental en la lucha por la desigualdad social, por lo que impulsa una política expansiva del gasto público en educación. La reducción del gasto público en educación se justifica, desde la posición economicista neoliberal, como un "crecimiento con menos escuela", contrapuesta a la posición reformista de un "crecimiento con más escuela" (García, 1991: 149). Países como Inglaterra, Estados Unidos de América y Australia han iniciado ese camino de reestructuración. Las políticas de contención y de "presupuesto equilibrado" han incluido dentro de sus prioridades la reducción de la tasa de crecimiento del gasto en educación desde finales de la década de 1970 (Sharp, 1988: 166).

\section{Individualismo posesivo y discurso político de la Nueva Derecha}

El discurso hegemónico de la Nueva Derecha, por el contrario, eleva a un rango de categoría totalizadora y universalista la visión individualista de la persona humana. Se ha venido enfrentando a la postura socialdemócrata que se aparta del inmanentismo y determinismo de la sujeción a las "leyes económicas", que le confiere a la voluntad humana la capacidad desde una dimensión ética (basada en 
valores como la equidad, el bien común, la justicia social, etc.) de transformar las condiciones objetivas de la vida social y las personas. Es posible, empero, encontrar distintas posiciones sobre este aspecto, como lo indica Goodwin:

\begin{abstract}
La libertad económica debe ser llevada al máximo, pero ¿qué pasa con la libertad personal? Algunos neoconservadores son con frecuencia libertarios, especialmente en los Estados Unidos, donde abogan por un mínimo de regulación gubernamental de la vida privada; pero en Gran Bretaña hay muchos nuevos autoritarios de derechas, como Scruton, que hace hincapié en la fidelidad, la tradición y la identidad nacional y promueve leyes más estrictas y menos salvaguardas para la libertad individual (1997: 203).
\end{abstract}

Para el neoliberalismo la libertad individual es el fundamento de la persona humana; este principio tiene su fundamento en la idea de que el ejercicio de esa libertad solo se puede potenciar al máximo en el marco del libre juego de las leyes naturales del mercado. Estas se tornan, desde esta perspectiva, en el marco natural de realización del individuo y la condición de posibilidad del progreso social. El discurso ideológico de la Nueva Derecha retoma la teoría política del individualismo posesivo, como una reacción a la incompatibilidad de su puesta en práctica en el contexto del capitalismo regulado. El eje articulador desde esa visión es la propiedad, la cual es concebida casi condición, sine quanon, en la concepción del individuo y de todo lo que gira alrededor de él: la sociedad, el Estado y desde luego la economía. Según esta tesis expuesta por Macpherson (1970) las condiciones de libertad y humanidad del hombre están determinadas por la propiedad exclusiva de su persona y la sociedad es en esencia una serie de relaciones mercantiles.

Offe (1990: 115-117) la concibe como una contradicción estructural del capitalismo del Estado del bienestar de naturaleza ideológica "en la infraestructura nornativa y moral de la sociedad capitalista", que presupone dos normas conexas que deben cumplir los actores individuales. La primera consiste en su deseo de utilizar las oportunidades que se les abren y en esforzarse por mejorar su posición en el proceso de intercambio (posesividad). La segunda, es que deben asumir una actitud favorable a aceptar cualquier resultado material que surja de la relación de intercambio, "especialmente si es desfavorable". Esta posición asume que los resultados deben atribuirse a "eventos naturales o a las virtudes y fracasos de los individuos (individualismo)". Asimismo, explica que una economía mercantil capitalista funciona si "el síndrome del individualismo posesivo se encuentra a la base de la conducta de los actores y en su interpretación de la conducta actual y futura de los demás”. ¿En qué consiste esa contradicción 
en un plano ideológico? Básicamente en la subversión del individualismo posesivo. Las relaciones de intercambio se "desnaturalizan", en virtud de que se crean y mantienen mediante estrategias estatales políticas y administrativas. Así, el valor de cambio de cualquier unidad de rabajo o capital en el mercado puede verse determinado, tanto por medidas políticas como por el manejo individual de las propiedades y recursos propios. Esto influye en que estos recursos se vean mediatizados y dependientes de las medidas políticas. Sobre esta cuestión Offe comenta:

Consideraciones como si pueden o no vender los individuos su fuerza laboral y cuánto reciben por ella, se van haciendo - a nivel de orientación normativa y auto-comprensión de los actores-más y más un asunto de políticas estatales adecuadas o inadecuadas en áreas como educación, formación profesional y desarrollo económico y regional. De modo semejante, para los propietarios de capital el éxito en el mercado depende menos de factores como disposición a asumir riesgos, inventiva, y capacidad para anticipar cambios en la demanda y más sobre políticas estatales en áreas como impuestos, tarifas, investigación y desarrollo e inversión en infraestructura (Offe, 1990: 116).

\section{Racionalidad económica neoliberal, meritocracia y legitimación}

Un rasgo inequívoco de la política económica de la Nueva Derecha es la reprivatización de sectores de la economía, capaces potencialmente de una adaptación a la forma de mercancía, tales como la sanidad, la educación, los servicios postales y telefónicos y otros del sector servicios (Sharp, 1988: 160). Esto se muestra ostensiblemente en el discurso antiestatista en los medios de comunicación que proclaman la supresión de las intervenciones sociales del Estado y la privatización masiva, entre otras medidas. Reprivatizar la educación es mercantilizarla y someterla a la lógica de la economía capitalista de mercado. Como lo hemos expresado en otra oportunidad:

Asi pues, estamos en presencia de una particular forma de concebir el cambio educativo en un contexto en el cual prima el imperio de la racionalidad económica sobre la social, la supremacía de libertad de quienes por su privilegiada situación económica pueden ejercerla sobre quienes no pueden por su situación de exclusión social, un cambio social cimentado en el interés individual sobre el interés colectivo, la concentración de la riqueza sobre la equidad y la justicia 
social, el utilitarismo económico y el afán lucrativo sobre la solidaridad social y el bien común, por mencionar apenas algunos aspectos de lo que se ha dado en llamar pensamiento 'social darwinista' de la derecha política (Miranda, 2001: 24).

Claus Offe identifica, incluso, dentro de las contradicciones estructurales del capitalismo tardío las estructuras organizativas del poder creadas por estrategias estatales reformistas, que responden al influjo del reduccionismo mercantilista. Al respecto indica:

Científicos sociales liberales tanto como marxistas han observado a menudo que bajo las condiciones del capitalismo tardio los sectores de la economía no controladas inmediatamente por mecanismos de mercado tienden a absorber una proporción cada vez mayor de la cantidad global de la fuerza laboral y producto social. El producto más obvio son la administración pública y todas las dependencias creadas y controladas por ella (como escuelas, servicios de transporte, oficinas de correo, hospitales, otros centros públicos, burocracias asistenciales, etc.). ¿Cómo explicar la importancia creciente de estas organizaciones? Expresado simplemente, se debe a que los intentos estatales por mantener y universalizar la forma mercantil requieren organizaciones cuyo modo de funcionamiento ya no se halle sometido a la forma mercantil (Offe, 1990: 115).

Desde la óptica de la mercantilización, el impacto de la privatización en la gestión de la crisis no ha demostrado ser significativo, sobre todo en proporcionar salidas a los excesos de capital (Amín, 1997). Sobre este aspecto Pérez Gómez afirma:

La escolarización es un instrumento al servicio del libre intercambio de una mercancía: la educación, cuya producción y distribución debe someterse a la libre regulación del mercado. Como cualquier otro producto considerado valioso individual o colectivamente, la mejor forma de garantizar su calidad es someterlo a la competencia del mercado (1999: 139).

De hecho, la lógica de los intereses del capital se define en aras de la gestión económica globalizada y en detrimento del Estado y, por ende, del sector público. Tal ha sido el caso de la educación en las sociedades neoliberales. 
La educación ha venido, en efecto, asumiendo de manera creciente un carácter utilitarista que, según Habermas (1972) tiene como correlato una visión burguesa que concibe la sociedad como un grupo instrumental que acumula la riqueza social exclusivamente como riqueza privada, centrando su dinámica para el rendimiento económico y el bienestar general por medio de la competencia entre particulares que actúan estratégicamente. En esta racionalidad social "los fines colectivos sólo pueden alcanzarse a través de la orientación de los individuos al lucro sobre la base de la propiedad" (Habermas, 1972: 143).

El modelo de sociedad que preconiza el programa político la Nueva Derecha posee un doble sentido, cuyas raíces se extienden a la racionalidad modemista: $1^{\circ}$ Es una combinación del arquetipo de la sociedad capitalista basada en la racionalidad económica liberal clásica heredera del pensamiento ilustrado. $2^{\circ}$ Es la vuelta a los fundamentos políticos, sociales y económicos de la democracia liberal en el contexto moderno de la sociedad racional, en los términos en que la definió Touraine (1993). En consecuencia, es un tipo de sociedad que niega toda acción a favor de la igualdad de oportunidades del reformismo, para dar paso a la racionalidad capitalista de las leyes del mercado. Empero, la visión del mercado como elemento vertebrador de la vida económica, se complementa con la visión neoconservadora que concibe la dinámica social como la suma de individuos motivados por intereses particulares. La racionalidad que justifica la vuelta renovada a las fuentes originales del capitalismo liberal, se justifica en el principio de que la desigualdad social es el resultado de un éxito o fracaso de los individuos en el mercado capitalista, es decir, es un hecho natural, una suerte de medición justa de los méritos personales. En esta tesitura, la escuela promueve la ideología de la movilidad social que Carnoy sintetiza en esta frase: "el único modo de tener éxito en una 'meritocracia' es conseguir el máximo de educación posible" (1999: 170). De esta integración de intereses surge una sociedad aún más deshumanizada que la que promovían los ideólogos del liberalismo clásico que justificaban su organización social en la racionalidad "natural" de las leyes económicas del mercado (tesis de la economía clásica).

No hay duda que la reacción lógica de las clases capitalistas al "resquebrajamiento" de las fibras morales de la sociedad mercantil capitalista, mediatizada por medidas de política estatal tendentes a universalizar y estabilizar la forma mercantil, que Offe (1990: 16) advertía, desde el año 1975, como un posible "foco de conflicto social y lucha política orientada a superar la forma mercantil como principio organizador de la reproducción social", ha sido uno de las manifestaciones más controversiales en el contexto de recomposición de las fuerzas sociales y de la actual estructura social de acumulación del capitalismo global. La respuesta ha sido que la Nueva Derecha ha canalizado 
los intereses elitistas de los grupos neoconservadores con un refuerzo de la racionalidad economicista de las políticas económicas neoliberales, formuladas alrededor del principio del libre mercado. En esta lógica se ha promovido un modelo educativo que fomenta la jerarquización y la división clasista.

El individuo privado, el homo economicus (del liberalismo económico clásico), elige de las múltiples alternativas para maximizar sus ganancias en el mercado mediante el ejercicio de la libertad de empresa, que se erige, asimismo, en otro de sus fundamentos esenciales del discurso de la Nueva Derecha. Esta racionalidad economicista por supuesto abarca la educación. Según Apple (1996: 45) el problema fundamental que se plantea la Nueva Derecha es cómo reorganizar el sistema educativo en torno a su sentido de las necesidades económicas, así "la educación se convierte en un producto como el pan o los coches y la única cultura de la que merece la pena hablar es la 'cultura empresarial' y las destrezas, conocimientos, disposiciones y valores flexibles necesarios para la competición económica". El conjunto de los capitalistas, como clase social, han tomado conciencia de la situación de sus intereses, por lo que adoptan un tipo de comportamiento colectivo tendente a salvaguardarlo, para lo cual se organizan y definen estrategias políticas y culturales específicas con arreglo a esos propósitos.

Tal como hemos visto, con la intención de socavar los valores de solidaridad que representaban la base de legitimización ética del Estado del bienestar (en el marco de la crisis económica de los setentas y los ochentas en los países de capitalismo avanzado), los grandes representantes del capital asumieron la posición de llevar adelante una gran ofensiva político-ideológica orientada a reducir los sectores no mercantilizados y a difundir valores individualistas posesivos. Esta reacción representa, tanto una contraposición a las políticas igualitaristas como una legitimación de sus intereses y privilegios clasistas. Por su parte, el neoconservadurismo apoyándose también en el individualismo propone el desarrollo de un espíritu emprendedor, por el cual los individuos deben alcanzar sus propias recompensas económicas, el prestigio social y el poder político (tesis meritocrática). Los neoconservadores son, al igual que los neoliberales, partidarios de la economía de mercado, aunque sus argumentos presentan lo que denominamos racionalización moralista: solo aquellos individuos que han hecho suficientes méritos por el esfuerzo personal merecen ser los beneficiarios de esas recompensas. Por ello, se insiste en el resurgimiento del espíritu de empresa privada mediante una reactivación moral: la restauración de una sociedad libre que amplíe la responsabilidad individual.

A este respecto Riutort (2001, 100-101) -apoyado en Offe- sostiene que el soporte social que gozaron las políticas sociales reformistas durante tantos años, incluso en el periodo de la crisis, se ha debido a "razones normativas compartidas 
por la mayoría de la ciudadanía" y no solo a razones de cálculo de cada individuo egoísta. Ese apoyo que parte de una suerte de identidad colectiva, de un "nosotros" que genera vínculos y normas solidarias es el que ha estado a la base de la expansión de las políticas sociales. Asimismo, apunta que las causas de la pérdida de consenso en las políticas sociales promovidas por la izquierda democrática se ha de buscar en los cambios normativos, que ha provocado la crisis económica y las transformaciones sociales que afectan la división del trabajo, la composición de las clases y de la cultura social y política. La conclusión a la que necesariamente se llega es que las transformaciones estructurales han producido "la descomposición de los vínculos y normas sociales sobre los que se sostiene la solidaridad de clase y las concepciones universalistas y humanistas que alimentan la identidad de masas adecuada a las políticas del bienestar". Finalmente, concluye Riutort, que una interpretación de la crisis de los setents en "clave neoliberal" viene a justificar esta descomposición y diseminación de la solidaridad universalista en el "egoísmo económico" que debilita las bases de legitimación ciudadana de las políticas de bienestar.

En la búsqueda del consenso a su programa político la Nueva Derecha afianza sus intereses mediante una estrategia electoral atractiva para las masas. El consenso para el apoyo social de base a su programa reside, como lo apunta Sharp (1988: 163), en "los fundamentos reales de la vida cotidiana bajo el capitalis$m o$ ". No se trata de una imposición desde arriba basada en una teoría de la conspiración (excepto cuando las condiciones exigen hacer uso del expediente del autoritarismo). Esta estrategia ha logrado captar en algunos casos fracciones como la pequeña burguesía (urbana y rural), sectores de las capas medias y otros grupos sociales, proclives a los "efectos de deslumbramiento" que la Nueva Derecha promueve en sus acciones de difusión ideológica-política, utilizando la mediación de las políticas educativas, desde el control del Estado.

\section{Referencias}

Amín, S. (1999). El capitalismo en la era de la globalización. Barcelona, Paidós.

Apple, M.W. (1996). Politica cultural y educación. Madrid, Ediciones Morata.

Apple, M.W. (2000). Teoría crítica y educación. Madrid, Ediciones Morata.

Bobbio, N. (1998). Derecha e izquierda. Madrid, Taurus. 
Carnoy, M. (1985). La educación como imperialismo cultural. México, Siglo XXI.

Eccleshall, R. (1993). “Conservadurismo”, en VV.AA.. Ídeologías políticas. Barcelona, Paidós.

Fernández Durán, R. (2001). “Capitalismo global, resistencias sociales y estrategias de poder”, en VV.AA. (2001). Globalización capilalista. Luchas y resistencias. Barcelona, VIRUS Editorial.

Fernández Enguita, M. (1985). Trabajo, escuela e ideología. Madrid, Akal.

García, E. (1991). "Reforma escolar, acumulación, legitimación y Estado del bienestar”, en VV.AA. Sociedad, cultura y educación. Madrid, CIDE-Universidad Complutense de Madrid.

Goodwin, B. (1997). El uso de las ideas políticas. Barcelona, Ediciones Península.

Gramsci, A. (1985). La alternativa pedagógica. Barcelona, Hogar del libro.

Habermas, J. (1999). Problemas de legitimación en el capitalismo tardío. Madrid, Ediciones Cátedra.

Laval, C. (2004). La escuela no es una empresa. Barcelona, Paidós.

MacPherson, C.B. (1970). La teoría política del individualismo posesivo. Barcelona, Fontanella.

Mandel, E. (1986). Las ondas largas del desarrollo capitalista. Madrid, Siglo XXI.

Moral Santín, J.A. y Raimond, H. (1986). La acumulación de capital y su crisis. Madrid, Akal.

Miranda Camacho, G. (2001). "La enseñanza comprensiva y el trasfondo sociopolítico de la crítica neoliberal”, en VV.AA (2001). Por una educación ciudadana. INETEMAS, Instituto de Estudios Transnacionales de Córdoba, España, Año VIII, Nº 21, septiembre de 2002. 
Navarro, V. (2000). Globalización económica, poder político y Estado del bienestar. Barcelona, Editorial Ariel.

Offe, C. (1990). Las contradicciones del Estado del bienestar. Madrid, Alianza Universidad.

Pérez Gómez, A. (1999). La cultura escolar en la sociedad neoliberal. Madrid, Ediciones Morata.

Riutort Serra, B. (2001). Razón política, globalización y modernidad compleja. España, El viejo Topo.

Sharp, R. (1988). Conocimiento, ideología y política educativa. Madrid, Akal.

Touraine, A. (1993). Crítica de la modernidad. Madrid, Temas de hoy. 